\title{
Learning from historic wooden structures: performance through hurricanes, earthquakes and other challenges in the tropics
}

\author{
D. Luna
}

San Juan, Puerto Rico

\begin{abstract}
The design, construction process, performance and materials of the historic wooden structures in Puerto Rico should be taken as an example. Their performance through hurricanes and earthquakes make them valuable in order to understand their success. This paper will highlight their qualities and the topics of materials, energy and water conservation, cross ventilation, construction details, structural details, restoration, reuse and human knowledge, from my personal experience in the restoration of my house. Every component of the wooden structures was designed with a specific purpose. The sustainable process requires learning from the efficiency of the past and reuse in the future.

Keywords: learning from the past, regional architecture, wooden structures, seismic vulnerability and vibrations, assessment, retrofitting and reuse of heritage buildings, material characterization and problems, performance and maintenance and environmental damage.
\end{abstract}

\section{Introduction}

Puerto Rico is an island surrounded by the Atlantic Ocean and the Caribbean Sea, located in the tropics. The island, approximately 100 miles east to west by 35 miles north to south, is bounded by offshore active faults on all sides. Population in Puerto Rico is approximately 4 million. Discovered in 1493 by Christopher Columbus, the island has developed into 78 municipalities in which San Juan is the Capital City. Since the $15^{\text {th }}$ century, structures in Puerto Rico have been constructed in wood, brick and stone. Through the small towns in the island wood houses are still standing as a living witness of our native architecture. 
Understanding design, construction process, performance and materials of those structures that have stood through strong hurricanes and earthquakes should be taken as an example. The discussion of topics as materials, energy and water conservation, cross ventilation, construction details, structural details, maintenance, restoration, reuse, retrofitting and human knowledge and sensibility, is very important for actual sustainable processes and economy.

The original materials and methods of construction in wooden historic structures that are still standing through the island and are naturally adapted to tropical climate should be documented. Every component of the structure was designed and built for a purpose. At the same time that efficiency was important; beauty and detail were relevant to human occupation and social status. The natural interior lighting prevails in many ways through particular elements such as "montantes" or transoms, fig. 1.

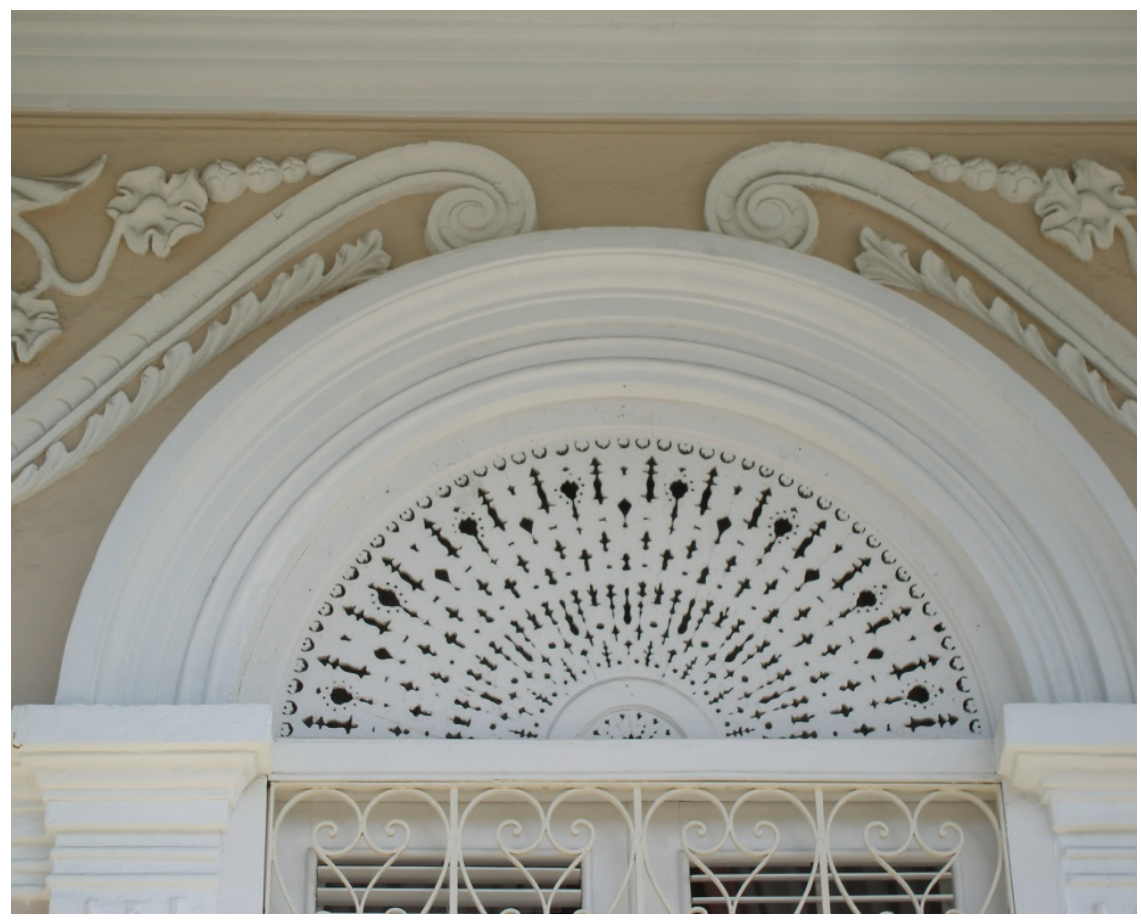

Figure 1: "Montantes", "Soles Truncos" or transoms. Picture by D. Luna.

Having practiced architecture for 24 years in Puerto Rico and being the owner of an 1882 wood historic house, I have lived through the process of restoration and the house has experienced all kinds of tropical challenges and earthquakes. Since personal experience is the best one, I have dedicated my professional life mainly to the restoration of historic wood structures. 


\section{History and typology of wood structures in Puerto Rico}

Since their foundation between the $17^{\text {th }}, 18^{\text {th }}$, and $19^{\text {th }}$ centuries most of the towns in Puerto Rico built their structures mainly in wood. It was the most abundant material on the island. Being a tropical island, forests are the dominant vegetation in the center of the mountains. Hard woods came from old trees as "caoba", "ausubo" or "moralón" and "capá". These woods were very hard and strong and they could resist force, weight, humidity and fire. The pieces had a lot of resin which made them really strong. So strong that today some of those woods are still standing and is very difficult to insert nails and screws in them.

These historic structures were the creation of the master builders. There is no architect named in the design and construction of the majority of those structures. My grandfather was one of those master builders and my father recollected the stories and the methods of construction from my grandfather. His work tools were my father's inheritance.

The style that we call "Criollo Vernaculo" is the most important one. Structures from the "Criollo" style were built between 1850 and 1925 in every town in the island. The "Criolllo" style is the Puerto Rican version of a mix of English, Spanish, French and North American influences adapted to the tropical climate. The floors, walls and roofs were built in wood. The foundations were tree trunks which were supporting the beams for the floor. Originally the floor of the balcony was in wood also but many of them disappeared as the status and progress were associated with cement and metal.

The roof structure was built in wood trusses and covered in the outside with wood shingles or corrugated metal. The form of the roof was in two or four slopes in order to resist winds and direct the water recollection to the cistern.

The "Criollo" houses were sustainable in terms of water and energy. Water was collected from the roof through a channel system that directed it to the cistern, fig. 2. The cistern was the deposit for all the water used in the house including the garden. The cistern usually had a filter in order to make the water suitable for drinking. The cistern was located in the backyard close to the kitchen and bathroom and usually was an independent structure. On some houses the cistern was elevated and distributed the water to the bathrooms and kitchen directly after filtering.

In terms of energy consumption, natural light was the main source of lighting during the day in the houses. Special openings in walls, roofs, doors and windows were designed and built to use natural light. During the night, candles were used to provide illumination. The hours of the day were used with efficiency; people woke up earlier and went to bed earlier too. In the kitchen, wood was the source for the fire.

The natural cross ventilation was one of the main purposes of the design. The interior spaces fluctuated between 12 and 16 feet high. The windows and doors provided all the ways to allow that cross ventilation. The house was located in order to receive the winds from the east and let them go by the west side. The windows and doors were located on opposite sides to facilitate the cross 


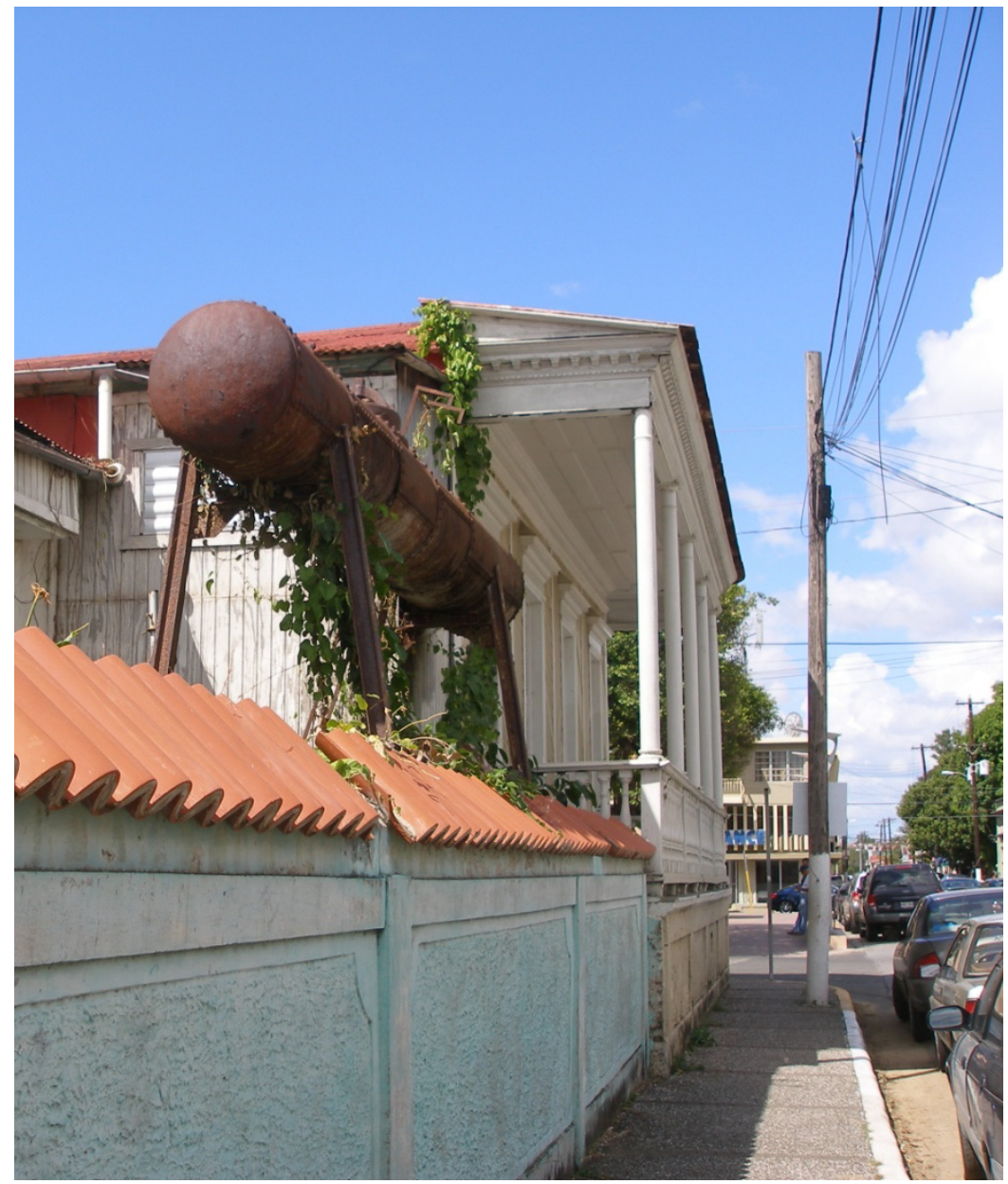

Figure 2: Water metal cistern. Picture by D. Luna.

ventilation. Special holes over windows and doors called "soles truncos" or "montantes" were located to help the cross ventilation.

The houses had a double roof, sometimes an attic, depending on the economic status of the owners and the square footage of the structure. The interior ceiling was the roofed the interior space. The sloped metal or shingle roof was the outside part. The space of the attic allowed cross ventilation and the hot air that was at the top of the interior space moved to the outside and also separated the interior space from direct sun light.

The "aleros" are the pieces over the windows and doors that protect the interior spaces from direct sun, rain and wind. The balcony in the front of the house was the first semipublic space that separated the outside or street from the interior of the house or private space. Sometimes visitors were received 
in the balcony of the house used as an outside living room and never entered the interior of the house.

The patio or backyard was an important part of the house, usually planted with herbs and medicinal plants. Also vegetables were planted there and basic food in order to deal with daily meals and in case of emergencies as hurricanes. Livestock were also part of the life in the patio.

The windows and doors were specially designed to serve several purposes. They could be open in full to let people and light in. They could open half of it vertically in order to keep some privacy. They could have the shutters open in order to control light and air. They could be all closed including the shutters in order to keep the interiors dark and get total privacy.

\section{Casa Luna}

The house of my family is called "Casa Luna". It is a wood structure built in 1882 in the historic urban center of Guayama. Guayama is a town founded in 1736 in the south coast of Puerto Rico.

Casa Luna has all the characteristic of a "Criollo Vernacular" house in Puerto Rico. It has a balcony along the north façade that face the street, fig. 3. The living room is centered in the main structure with two private rooms at each side. The gallery is an open hallway that connects the main living room with the kitchen, bathroom, and the rest of the house. At one side of the gallery is the patio. The structure is raised 24 inches from the ground in order to let cross ventilation underneath and ventilate the wood floors.

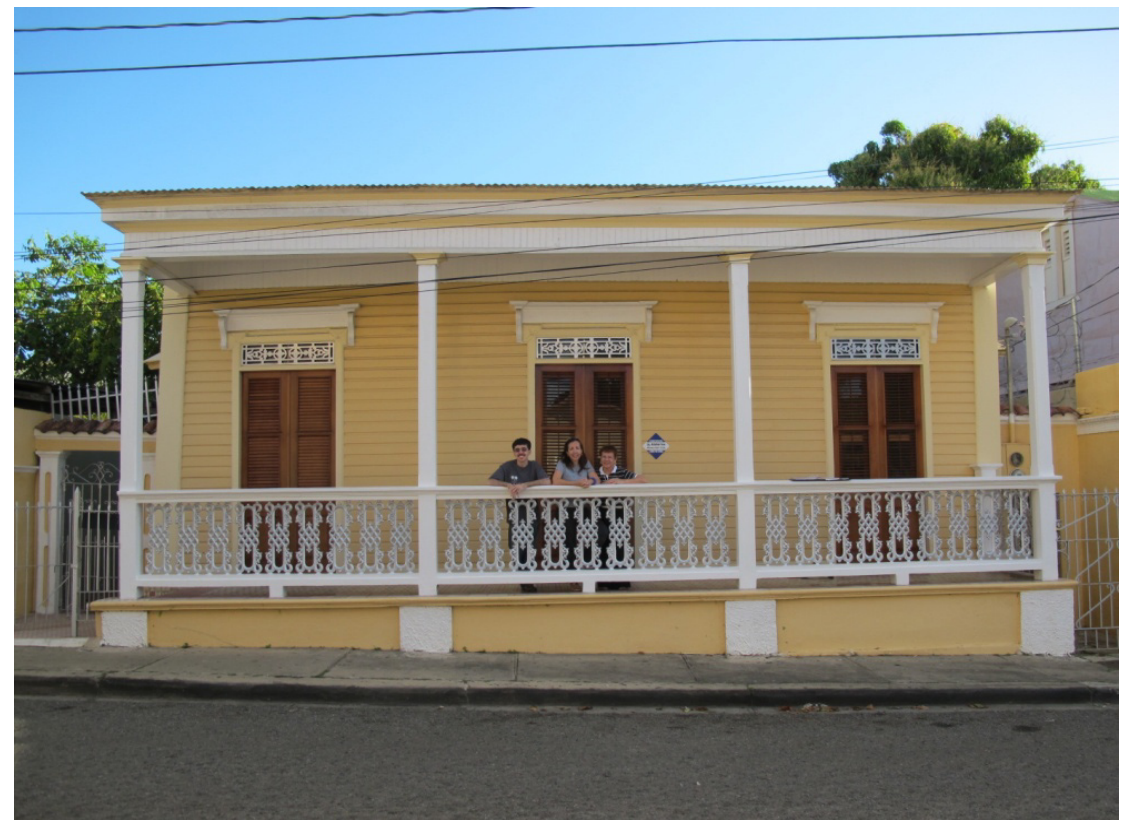

Figure 3: $\quad$ Casa Luna, picture by D. Luna. 
Casa Luna received some alterations over the years but in 1993 when I graduated from the School of Architecture. I decided to initiate a restoration process in order to have the experience first hand. The restoration took almost one year, some windows and doors that were removed during its lifetime were reproduced as the original ones. The front façade was restored to the original of 1882. The wood floors were restored; historic paint in the interiors was recovered and restored. The gallery and the patio were also restored and recovered. The original trees trunks at the foundations were restored cleaned and relocated in the same place since the house had suffered a leveling condition. After a detailed historic study of archives and other resources all the alterations in the structure were documented and restoration was completed. Most of the original wood was preserved in order to comply with real conservation of the original material.

In 1993 the restoration process for "Casa Luna" was submitted to the National Trust for Historic Preservation Awards in the interiors restoration category. The house won the second place. Since then other houses had been saved by the example of "Casa Luna".

\section{Earthquakes in Puerto Rico}

Puerto Rico is located between the plates of North America and the Caribbean. There are numerous local and regional events in the recorded history with magnitudes more than 7.0, some of which have generated tsunamis. In the $20^{\text {th }}$ century we have had more than four from 7.4 to 7.8 on the Richter scale. The biggest one was felt onshore in 1918 on the west coast of the island [1].

The U.S. Geological Survey hazard maps indicate that the seismic hazard is similar to the Basin and Range province in the Western United States. The island is assigned Seismic Zone 3 in the current standard building code in Puerto Rico, the 1997 UBC [1].

According to the Puerto Rico Seismic Network during the year 2009; 1,153 movements were registered, 15 were felt by the public. People in Puerto Rico are aware of the consistency and magnitude of all the movements recorded constantly. Between 2006 and 2009; 7,513 movements were registered of different magnitudes. During the $20^{\text {th }}$ century no wooden structure has collapsed due to an earthquake [1].

\section{Hurricanes in Puerto Rico}

Hurricanes and other phenomena form in the tropical areas of the Atlantic Ocean, Gulf of Mexico and the Caribbean Sea. They initiate between the latitudes 10 and 30 over the Equator. There are five different phenomenon that are related to tropical disturbances: waves, disturbances, depressions, storms and hurricanes. Of all of them the hurricanes are the strongest and destructive. Hurricanes are classified in five categories according to the wind force in their cores. Category number 5 is the most devastating with winds of 155 miles per hour and more. Category 4 hurricanes have winds between 131 to 155 miles per hour [2]. 
Hurricane season every year goes through the months of June until November in Puerto Rico. In the history of the $20^{\text {th }}$ century, Puerto Rico experienced one category 5 hurricane in 1928, one category 4 in 1989 and two category 3 hurricanes in 1932 and 1998 [2].

\section{Performance of a wood structure through an earthquake}

Every day in Puerto Rico there are at least 3 movements in the range of 3 in the Richter scale [1]. The land is in constant movement here. Movement is natural in a wood structure.

The structure of a wood house is also a design to learn from. Original joints were all in wood. Wood inserted in wood like an interwoven tissue. No nails or screws were used in the earlier structures. Those kinds of joints were the ones

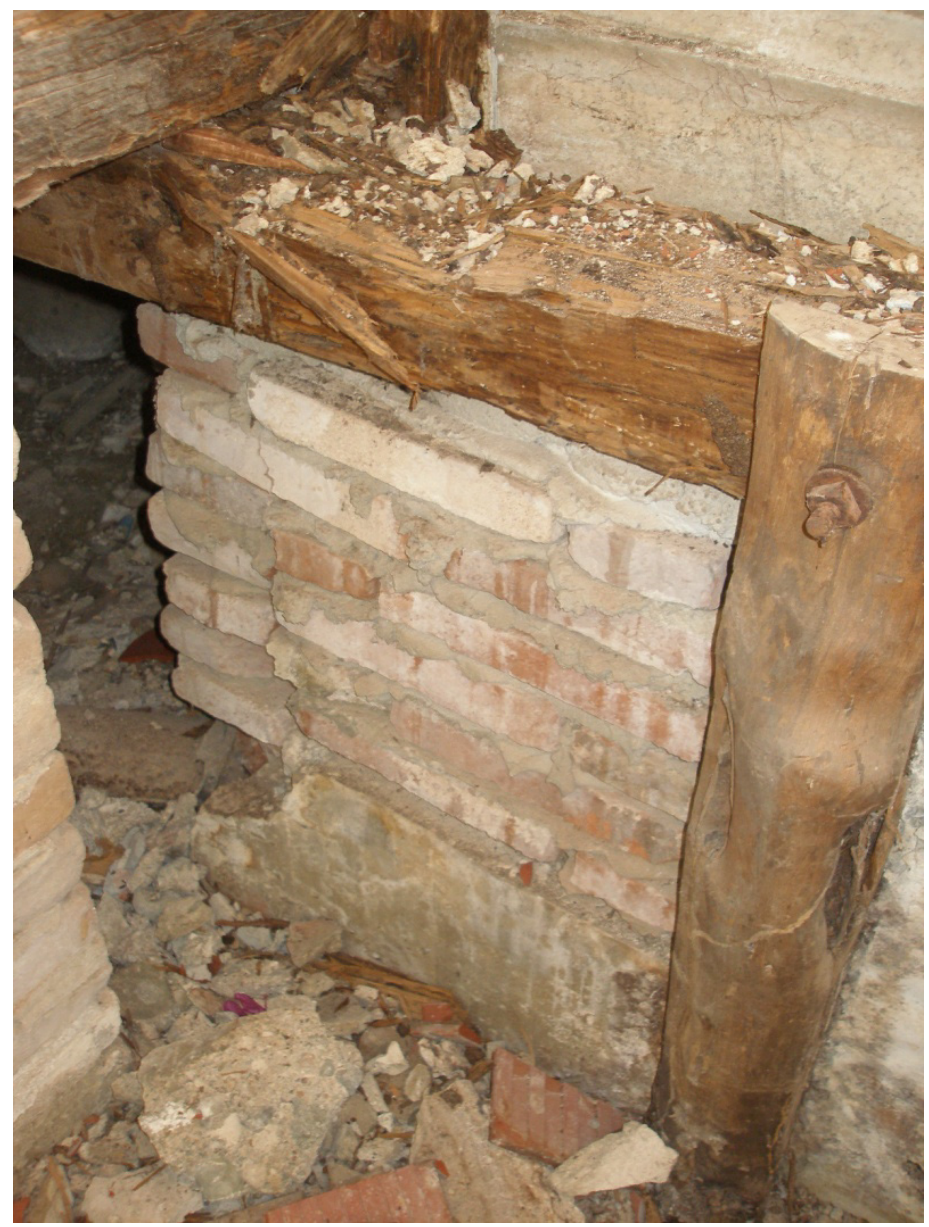

Figure 4: $\quad$ Tree trunk foundation. Picture by D. Luna. 
that gave resistance to the whole structure making the structure rigid but at the same time giving flexibility for some movement when needed. Those small movements were needed in case of an earthquake.

From the foundations that were tree trunks inserted in the tamped soil, joints with the beams that supported the interior floor were inserted in the wood, fig. 4 . The beams blocked the movement of the columns in two directions.

The walls were built over the outside beams but there was an interior wall and an outside wall for the exterior. The space between the two walls served for two purposes, resist movement for the wall lying in a double layer and protect the interior temperature.

At the top of the walls, the beams for the roof were supported by the columns distributed to the body of the building. These columns did not make it directly to the ground or foundations which make the structure flexible for some movement. The structure of the roof was made of individual trusses. All the joints through the whole structure were the same, wood inside wood, sometimes with screws, fig. 5. Other joints were wood lying over wood.

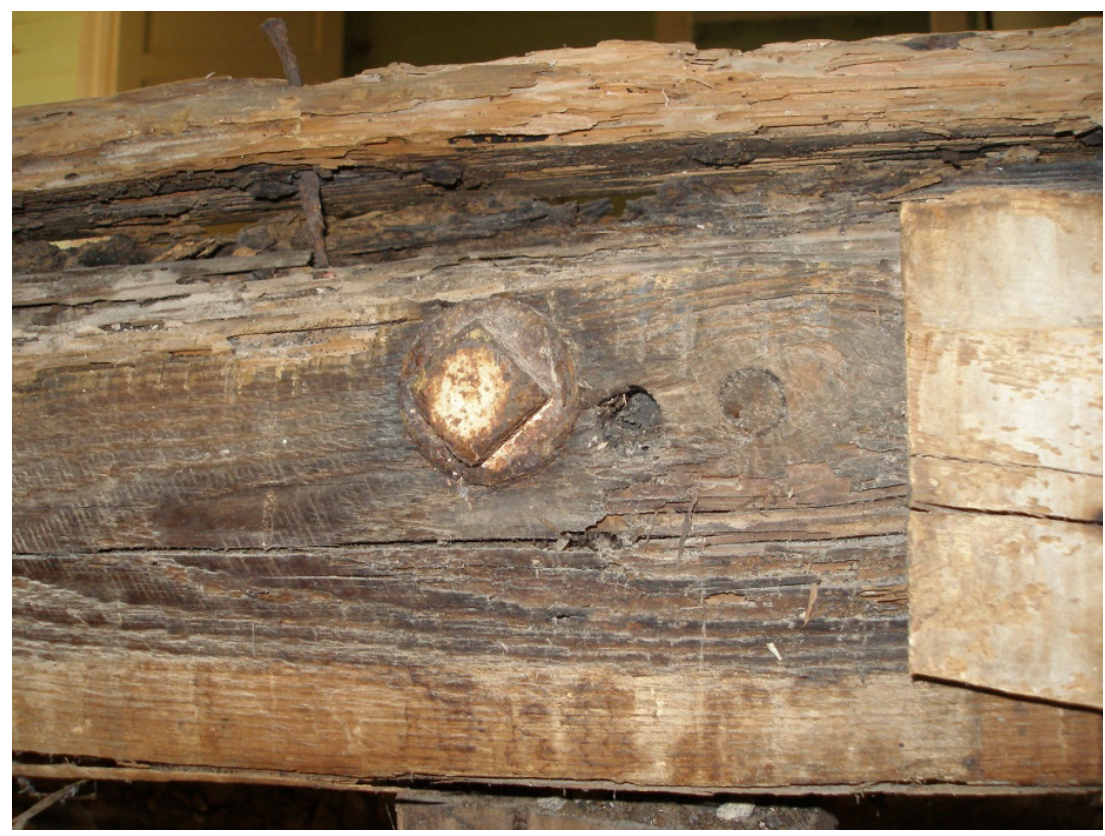

Figure 5: Joint. Wood with old screw. Picture by D. Luna.

This type of construction permitted separate movements of the structure over the whole building. This condition also permitted restoration of individual pieces without damaging additional material.

In "Casa Luna" the movement over 110 years made the structure inclined 3 inches in one corner. In the restoration of 1993, all the columns were leveled in order to fix the leveling and make the floors even. 


\section{Performance of the wood structures during a hurricane}

Our historic wood structures from 1850 have been resisting the four mayor hurricanes that affected Puerto Rico. Winds of 155 miles per hour at least were developed during a hurricane in 1928 [2].

Some of the characteristics that able the structures to resist and stand were the shape of the roof. The pitch roof was designed and built in a way to make it aerodynamic. Other characteristics were the openings in the attic, the top of the windows, and the opening in the sub-base. The way the openings in the structure were distributed permitted the wind to go through some parts of the structure and release the forces. Over the openings of doors and windows there was an outside door. This doors had two solid wood leafs; they were called the storm shutter or "tormentera". Those leaves were permanent to the structure. They stayed always in the open position but were closed in an event of an emergency. When the shutters were closed they used a permanent piece of wood horizontally called "tranca" which sealed from the inside the door or the window. The way they were operated and closed made them impervious to hurricanes.

Some houses had an opening or door on the floor into the foundation in which a space was built in brick. This space was a bunker for the inhabitants, in case the structure could not resist the winds. This space was called also the "tormentera". It was a hidden place in many cases.

During several hurricanes I stood inside "Casa Luna" with all the shutters closed and experiencing the performance of the structure. The crackle of the wood and the sound of the winds were impressive, the movement of air could be described as a flow. The openings in critical places and the closure in the others only for protection of the interior, made the wind and rain go through the parts of the house just the adequate way to let it stand and resist.

\section{Sustainability and the historic wood structures}

In times where sustainability, reuse and recycle are a necessity, historic wooden structures comply with all three of them.

Living in the tropics and dealing with earth movements daily and hurricanes and other tropical disturbances. The way the historic wood structures solved all these issues is quick and efficient way to start the solution. The simple way these structures dealt with complex issues such as hurricanes and earthquakes that could destroy, shatter and destroy lives, make it imperative to take a closer look at the scene.

It is necessary to say that preserving the existing wood or reusing existing wood is imperative in order to make it sustainable. The deforestation is not an alternative any more in Puerto Rico. In order to preserve the wood structure is necessary to reuse the same wood or preserve it with current techniques. Saving the material and not using new one, is part of the process of sustainability. Learning from the managing of the waters and energy conservation through the structure, is a marvel that can be reproduced easily today. Installing solar panels into the exterior roof could easily make the structure completely sustainable. 
The home garden cultivating vegetables and some food is an immediate alternative to food supply.

\section{Conclusions}

Learning from the past is essential to get into the actual and future of sustainable restoration. It is not optional it is a moral responsibility. A simple structural and architectural solution adapted to the tropical climate has been done since the $17^{\text {th }}$ century and it has survived earthquakes and hurricanes, fig. 6. Educating and recognizing our architectural history could help solving our climate crisis. In that same spirit our culture and our history could be saved for the future.

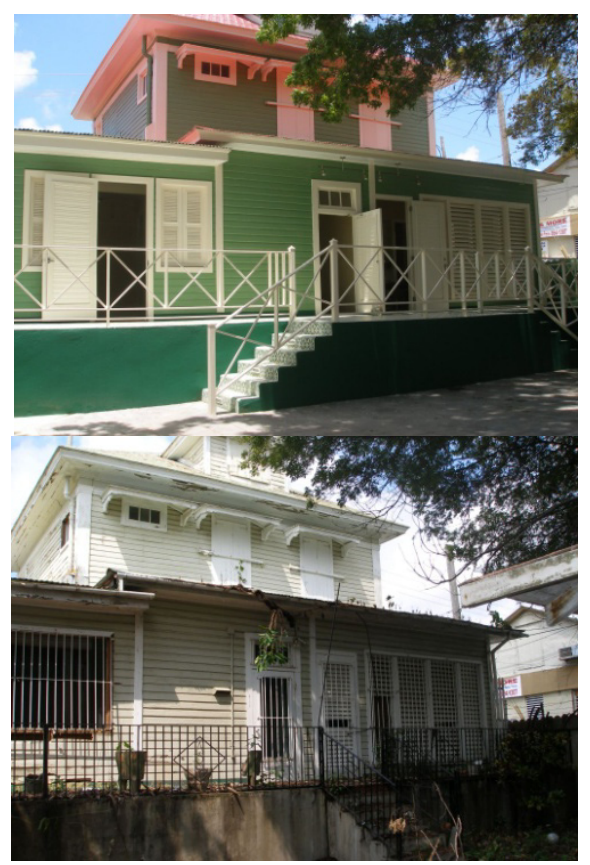

Figure 6: Actual and previous condition of a wooden historic structure. Picture by D. Luna.

\section{References}

[1] Puerto Rico Seismic Network, University of Puerto Rico, Mayaguez Campus, Department of Geology. www.redsismica.uprm.edu

[2] FEMA, www.fema.gov 